\title{
PERFORMANCE ANALYSIS OF REGIONAL BUDGETARY POLICY
}

\author{
Lyudmila M. Borsch \\ V.I. Vernadsky Crimean Federal University, Simferopol, Russian Federation \\ Svetlana V. Gerasimova \\ V.I. Vernadsky Crimean Federal University, Simferopol, Russian Federation
}

\begin{abstract}
The article examines the actual scientific and practical problem of budgetary regional policy, the formation and use of a consolidated budget as an effective mechanism for allocating the budget to the municipal territories of the region. The effectiveness of the regional budget policy is influenced by the monetary policy of the central bank, which performs an important function of managing the monetary sphere, using tools and methods that affect socio-economic development with the use of complex processes of influencing the processes of reproduction, which determines the relevance of this study. The aim of the study is to develop tools, use them in budgetary policy in the formation of a consolidated budget, ensure economic development and social standards of the population. The novelty of the research is the application of a synthesis of systemic and institutional approaches based on the specifics of budget policy and the mechanisms of their formation. As a result of the study, an analysis of the formation of a consolidated budget and its use was carried out, using tools and mechanisms of influence, through which adjustments are made to maintain macroeconomic equilibrium and effective development based on their own laws that arise within the economic system. Reproduction processes occur within the economic system and form a complex system of economic development, which is subordinated to the influence of methods and tools, acquiring a new architecture in the management system. Through the provision of development processes, new approaches are being built and created, strengthening competitive advantages in the economic system of regional development. The region is strengthening its position and is able to compete in the market, meet consumer demand, influence the development of the domestic market, ensuring the socio-economic development of the region. Dominant use of budget methods of direct and indirect incentives comprehensively ensures the socio-economic development of the region. The research was carried out on the basis of indicators of the Republic of Crimea, which are in the public domain.
\end{abstract}

Key words: direct and indirect methods, budget policy instruments, consolidated budget, social and economic development, criteria, monetary policy, reproduction processes.

Citation. Borsch L.M., Gerasimova S.V. Performance Analysis of Regional Budgetary Policy. Vestnik Volgogradskogo gosudarstvennogo universiteta. Ekonomika [Journal of Volgograd State University. Economics], 2021, vol. 23, no. 1, pp. 87-101. (in Russian). DOI: https://doi.org/10.15688/ek.jvolsu.2021.1.7

УДК 332.12

Дата поступления статьи: 27.11.2020

సิ ББК 65.04

Дата принятия статьи: 11.12.2020

\section{АНАЛИЗ ЭФФЕКТИВНОСТИ РЕГИОНАЛЬНОЙ БЮДЖЕТНОЙ ПОЛИТИКИ}

\author{
Людмила Михайловна Борщ
}

Крымский федеральный университет им. В.И. Вернадского, г. Симферополь, Российская Федерация

\section{Светлана Васильевна Герасимова}

Крымский федеральный университет им. В.И. Вернадского, г. Симферополь, Российская Федерация

Аннотация. В статье исследуется актуальная научно-практическая проблема бюджетной региональной политики, формирование и использование консолидированного бюджета, как эффективного механизма рас- 
пределения бюджета по муниципальным территориям региона. На эффективность региональной бюджетной политики влияет денежно-кредитная политика центрального банка, которая выполняет важную функцию управления денежно-кредитной сферой, используя инструменты и методы, влияющие на социальноэкономическое развитие с применением комплексных процессов влияния на процессы воспроизводственной деятельности, что определяет актуальность данного исследования. Целью исследования является разработка инструментов влияния и их применение в бюджетной политике при формировании консолидированного бюджета с целью обеспечения экономического развития и социальных стандартов населения. Новизной исследования является применение синтеза системного и институционального подходов, опирающихся на особенности бюджетной политики и механизмов их формирования. В результате исследования был проведен анализ формирования консолидированного бюджета и его использования с применением инструментов и механизмов влияния, посредством которых вносятся корректировки для поддержания макроэкономического равновесия и эффективного развития на основании собственных закономерностей, возникающих внутри хозяйствующей системы. Выводы. Процессы воспроизводства происходят внутри хозяйствующей системы и формируют комплексную систему экономического развития, которая подчинена воздействию методов и инструментов влияния и тем самым приобретает новую архитектуру в системе управления. Посредством обеспечения эволюционных процессов происходит формирование новых подходов, выстраиваются и создаются новые программы по эффективному управлению и совершенствованию, укрепляющие конкурентные преимущества в хозяйственной системе регионального подъема. Регион укрепляет свои позиции, способен конкурировать на рынке, удовлетворять потребительский спрос; влиять на расширение внутреннего рынка, обеспечивая социально-экономическое развитие региона. Доминантное использование бюджетных методов прямого и косвенного стимулирования комплексно влияет на обеспечение региональных воспроизводственных процессов в экономике. Исследования проведены на основании показателей Республики Крым, находящихся в открытом доступе.

Ключевые слова: прямые и косвенные методы, инструменты бюджетной политики, консолидированный бюджет, социально-экономическое развитие, критерии, денежно-кредитная политика, воспроизводственные процессы.

Цитирование. Борщ Л. М., Герасимова С. В. Анализ эффективности региональной бюджетной политики // Вестник Волгоградского государственного университета. Экономика. - 2021. - Т. 23, № 1. - С. 87-101. DOI: https://doi.org/10.15688/ek.jvolsu.2021.1.7

\section{Введение}

Развитие бюджетной политики на современном этапе формируется на основе совершенствования науки, техники и технологий. В основу бюджетной политики заложено бюджетное планирование, которое позволяет регионам применять свои особенные методы, с их помощью формируется доходная часть бюджета, которая должна быть достаточной для обеспечения выполнения социальных стандартов региона.

Следует отметить, что бюджетные ресурсы в регионах формируются за счет воспроизводственных процессов, развития отраслевых экономик и внутреннего роста валового продукта с применением комплексных методов управления всей экономической региональной системой. Региональная система функционирует на программах социально-экономического развития региона, региональных и федеральных программ развития, определяя источники формирования бюджетных ресурсов.
Исследуемый регион (Республика Крым) имеет свою отличительную черту при формировании бюджетной политики, он достаточно специфичен по сравнению с другими регионами. С начала 2014 г. для развития региональной политики исследуемого региона использовалась методика формирования бюджетных отношений, в основе которых применялись монетарные принципы государственного регулирования. Накопленный опыт региона изменил систему управления бюджетными средствами, уже в 2017 г. начал формироваться механизм регулирования экономических отношений между субъектами хозяйственной деятельности внутри региона.

Определяющим направлением повышения эффективности региона стало решение основных вопросов наполняемости и распределения финансовых ресурсов с применением планирования и прогнозных данных. Главными задачами регионального развития являются качество, взаимопонимание и взаимодействие между ветвями власти на уровне 
региона, муниципальных образований и городских округов. Менеджмент управления, консолидации бизнеса и власти влияет на формирование консолидированного бюджета и его эффективное использование и способствует социально-экономическому развитию. Для реализации данных задач управление муниципальными образованиями не всегда бывает эффективным и часто носит формальный характер. Отношение к кадровой политике долгое время рассматривается как необязательное управление, основной менеджмент сосредоточен в экономическом блоке, который требует существенных финансовых ресурсов, а для их рационального использования, как правило, не хватает эффективного управления.

\section{Бюджет как источник финансовых ресурсов}

Исследования показывают, что эффективных результатов в области применения бюджетной политики можно достичь при помощи совершенствования методов взаимодействия региональных и федеральных законодательных органов, муниципальных и региональных органов власти и субъектов хозяйствования малого и среднего бизнеса. Каждая успешно развивающаяся территория преследует главную цель, которая определяется уровнем жизни населения и последовательным решением вопросов социально-экономического развития региона. Бюджетная политика направлена на формирование консолидированного бюджета, распоряжение бюджетными средствами, предоставляя муниципальным образованиям трансферты в виде: дотаций, субвенций, субсидий, кредитов и иных межбюджетных трансфертов (далее - МБТ). Муниципальные образования должны выполнять свои основные функции, определенные нормативно-правовыми актами, регламентами, уставом, создавая благоприятный инвестиционный климат, развивая инфраструктуру, формируя инвестиционную культуру на предприятиях и социальных группах, у населения.

Методологической основой данного исследования является синтез системного и институционального подходов; метод анализа имеющихся в открытом доступе информационных источников статистических данных в раскрытии теоретико-методологических основ ведущих экономистов по вопросам развития бюджетных отношений и их влияние на социально-экономическое развитие. Всестороннее исследование теории и практики поспособствовало выявлению проблем, которые находятся внутри региональной системы. Применялись методические подходы к формированию консолидированного бюджета, распоряжение бюджетом и влияние бюджетных трансфертов на социально-экономическое развитие муниципальных образований, формированию подходов при осуществлении бюджетной политики.

\section{Теоретические и прикладные методы} прямого, косвенного

\section{и бюджетного регулирования}

Основными задачами региона и его подсистем являются качество, взаимопонимание и взаимодействие между ветвями власти на уровне региона, муниципальных образований и городских округов. Менеджмент управления, консолидации бизнеса и власти - это составляющие, которые влияют на формирование консолидированного бюджета и его эффективное использование. Применение прямых и косвенных методов способствует социальноэкономическому развитию. В направлении эффективного управления муниципальными образованиями вели свои исследования Л.М. Борщ [Борщ, 2019, с. 5-12], Т.Н. Бугаева [Бугаева, 2019, с. 23-31], Д.Д. Буркальцева [Буркальцева, 2017, с. 79-82], Е.И. Воробьева [Воробьева, 2020, с. 5-12], М.Н. Дудин [Государственный фискальный контроль ..., 2017, с. 160-169]. Данные работы поспособствовали тому, чтобы авторы, применяя информационные источники, сформировали институциональный подход.

Исследования ведущих экономистов в области воспроизводственных процессов с применением методов, инструментов по формированию консолидированного бюджета как источника финансовых ресурсов, которые нужны для развития территорий, последовательно решают социальные вопросы социальноэкономического развития региона, преследуя главную цель - определить уровень жизни населения: [Борщ и др., 2016, с. 71-76; Заи- 
ченко и др., 2016, с. 71; Колбина, 2016, с. 1115; Савинкова и др., 2017, с. 39-42; Тажитдинов, 2013, с. 17-27; Савина и др., 2018, с. 129 138; Родионова и др., 2015, с. 138-141]. Именно указанные процессы формирования консолидированного бюджета и эффективное использование финансовых ресурсов составляют основу социально-экономического развития.

Исследования муниципальных образований определяют процессы их деятельности, регулируются нормативно-правовыми актами, регламентами, уставом, их деятельность направлена на создание благоприятного инвестиционного климата, развитие инфраструктуры, формирование инвестиционной культуры на предприятиях, у населения, поддерживая уровень макроэкономического равновесия и влияя на социально-экономическое развитие экономики. Данные направления исследований рассматривались ведущими экономистами: [Воробьев и др., 2018, с. 56-75; Галюкшова, 2014 , с. 157-162; Заиченко, 2016, с. 72; Митрофанова, 2018, с. 75-84; Ильин, 2014, с. 118-121; Мосейкин, 2014, с. 163-167; Чернова и др., 2018, c. 65-74; Тараканов, 2016, с. 98-105].

Рассмотрим бюджетные методы прямого и косвенного стимулирования социально-экономического регионального развития экономики. Исследования показывают, что в процессе применения методов и инструментов влияния определяются источники финансовых ресурсов, происходит процесс формирования критериев, разрабатывается механизм, который влияет на расширенные воспроизводственные процессы. Существуют прямые и косвенные методы бюджетного стимулирования (см. таблицу).

Исходя из таблицы, прямые методы (как цель) выполняют свою особую функцию воздействия и укрепления конкурентных преимуществ в производственной экономической системе. Они формируют доходную часть бюджета, что в дальнейшем приводит к процессу перераспределения финансовых ресурсов для следующего процесса потребления данного ресурса в процессе перераспределения. На региональном уровне цель применения косвенных методов влияет на процессы воспроизводства, обновления производственных мощностей, развития цифровой инфраструктуры, процессы модернизации, что в свою очередь влияет на приток инвестиций в регион как внутренних, так и иностранных, способствует формированию новых бюджетных, межбюджетных отношений в регионе, создавая новую архитектуру управления экономическим развитием и формированием бюджетной региональной политики.

Применение методов бюджетного регулирования направлено на процессы формирования бюджетных ресурсов, которые по перераспределению реализуются в региональных программах социально-экономического, инфраструктурного, технологического, инноваци-

Таблийа

\section{Методы прямого и косвенного бюджетного регулирования и стимулирования}

\begin{tabular}{|c|c|c|}
\hline Методы влияния & Цель направления метода & $\begin{array}{c}\text { Применение методов } \\
\text { бюджетного регулирования }\end{array}$ \\
\hline $\begin{array}{l}\text { Применение прямых } \\
\text { методов влияния }\end{array}$ & $\begin{array}{l}\text { Усиление конкуренции, модернизация } \\
\text { производственных процессов; социаль- } \\
\text { ные стандарты и гарантии региона; фор- } \\
\text { мирование цифровой и инновационной } \\
\text { инфраструктуры; применение ключевых } \\
\text { компетенций в системе управления инве- } \\
\text { стициями и инновациями }\end{array}$ & $\begin{array}{l}\text { Региональные программы социально- } \\
\text { экономического развития; федеральные } \\
\text { программы социально-экономического } \\
\text { развития; государственное законодатель- } \\
\text { ство по выравниванию регионального } \\
\text { обеспечения в виде дотационных регио- } \\
\text { нов, к такому регулятору относятся суб- } \\
\text { венции, субсидии, трансферты }\end{array}$ \\
\hline $\begin{array}{l}\text { Применение в ре- } \\
\text { гионах косвенных } \\
\text { методов влияния }\end{array}$ & $\begin{array}{l}\text { Применение налоговых льготных «кани- } \\
\text { кул» для предприятий свободной эконо- } \\
\text { мической зоны (СЭ3); снижение или от- } \\
\text { срочка платежей на определенные перио- } \\
\text { ды (земельный налог); другие социально } \\
\text { значимые льготы, поддерживающие ста- } \\
\text { бильность в развитии }\end{array}$ & $\begin{array}{l}\text { Функция системы налогообложения как } \\
\text { инструмент и механизм одновременно } \\
\text { находится в состоянии регулятора; в сфе- } \\
\text { ре политики ускоренной амортизации; } \\
\text { кредитно-денежной политике }\end{array}$ \\
\hline
\end{tabular}

Примечание. Составлено авторами. 
онного, промышленного и сельскохозяйственного развития. Федеральные программы социально-экономического развития являются стратегическими, и результаты их реализации дают толчок любому региону усиливать конкурентные позиции не только на внутреннем рынке страны, но и за его пределами. Данные программы имеют длительный жизненный цикл активного производственного процесса, с момента введения такого проекта он становится одним из источников наполнения доходной части бюджета региона и выхода региона на новый уровень развития. Такие федеральные проекты являются точками роста регионального развития, которые подтягивают развитие других производственных и непроизводственных сфер деятельности. Формируется цифровая инфраструктура, обеспечивающая процессы воспроизводства и роста потребительского спроса, что наполняет доходную часть бюджета региона для его последующих этапов развития, поэтому федеральные программы и Стратегия социально-экономического развития Российской Федерации до 2030 г. носят комплексный характер, направленный на укрепление регионального развития на долгосрочной основе [Воробьев и др., 2018, с. 57].

Российская экономическая система активно участвует в развитии Евразийского экономического союза, созданное пространство влияет на формирование и укрепление финансовой и транспортной системы, формируется единый энергетический рынок, что приводит к развитию экономики страны в целом. Разрабатываются новые торговые коридоры, данные процессы и торговые связи поддерживают торговлю не только со странами Евразийского экономического союза, но и с другими странами, не входящими в Евразийский экономический союз. Разрабатываются новые алгоритмы системных ключевых показателей эффективности функционирования финансовой системы, что влияет не только на развитие государственной финансовой системы, это затрагивает каждый регион.

Государственная политика относительно приоритетов в российской экономике последовательно и уверенно взяла курс на снижение процентных ставок для кредитов в воспроизводственные процессы, инновационную деятельность, импортозамещение, что непременно даст определенные результаты в социаль- но-экономическом развитии. Формами бюджетного регулирования являются: вертикальное бюджетное регулирование (передача частей налогов с одного уровня на другой); горизонтальное бюджетное регулирование (межбюджетные трансферты), предоставление бюджетных кредитов.

\section{Источники формирования бюджетных и межбюджетных трансфертов муниципальных районов}

Анализируя источники формирования бюджетных трансфертов, следует уточнить, что данная деятельность осуществляется на основании бюджетной политики, Бюджетного кодекса в соответствии с Приказом Министерства финансов Российской Федерации от 22 декабря 2010 года. Данный отчет составляется и предназначен для анализа и информации об источниках предоставления межбюджетных трансфертов. Всего МБТ по состоянию на 01.06.2020 предоставлено 10 956,13 млн руб., из них дотации - 413,66; субсидии - 621,27; субвенции - 9790,47 ; иные МБТ - 131,03. Межбюджетные трансферты из бюджета Республики Крым за исключением субвенций [Нормативный процесс ...] предоставляются в соответствии с законодательством Российской Федерации о налогах и сборах [Комментарий к ...], что определено законом межбюджетных отношений Республики Крым, который принят Государственным Советом Республики Крым от 12 ноября 2014 г. [Нормативный процесс ...].

Исполнение консолидированных бюджетов в Республике Крым в разрезе бюджетов муниципальных районов отражено на рисунке 1.

Согласно статистическим показателям рисунка 1, можно констатировать факты, что не все муниципальные районы развиваются равномерно, динамику темпов прироста имеют Бахчисарайский, Советский, Симферопольский, Первомайский, Нижнегорский, Джанкойский, Белогорский, Красноперекопский, Раздольненский муниципальные районы. Также можно дать объяснения тому, что плановые показатели не выполнены вследствие развития пандемии коронавируса в регионе, что поспособствовало снижению потребительского спроса на промышленные товары, многие 


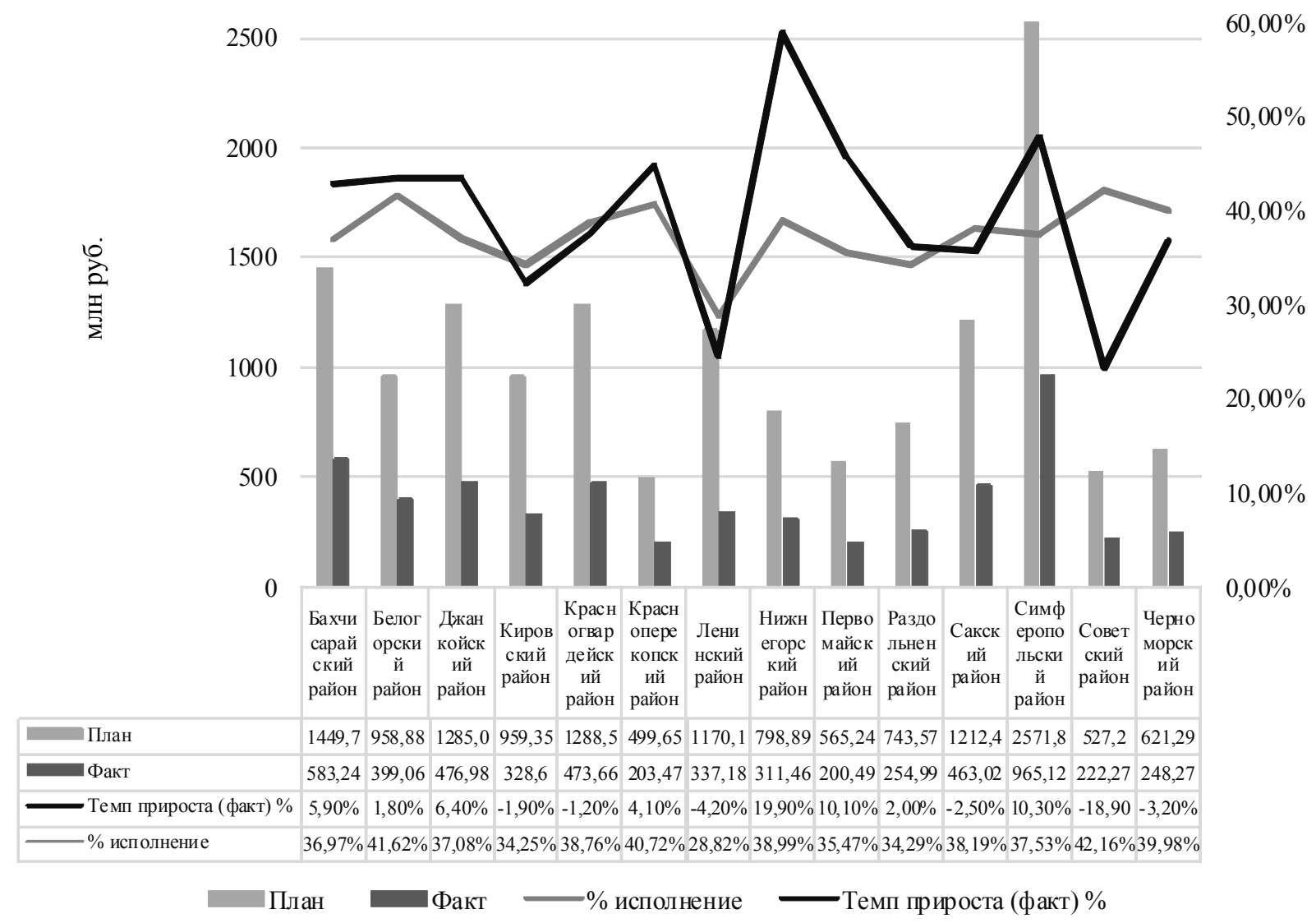

Рис. 1. Межбюджетные трансферты по муниципальным районам по состоянию на 01.06.2020

Примечание. Составлено авторами по: [Официальный сайт Открытого бюджета ...].

предприятия были на вынужденном карантине, что повлияло на выполнение плановых показателей. Применение межбюджетных трансфертов предоставляемых региональными министерствами финансов по бюджетному законодательству предоставляются муниципальным образованиям в соответствии с Бюджетным кодексом Российской Федерации, Федеральным законом «Об общих принципах организации местного самоуправления в Российской Федерации» от 6 октября 2003 г. № 131 (157) и Постановления Совета министров Республики Крым от 9 февраля 2018 г. № 56 [Официальный сайт Министерства экономического развития ...]. Межбюджетные трансферты по городским округам (см. рис. 2) имеют минусовые темпы прироста, в частности, города Армянск, Джанкой, Евпатория, Керчь, Красноперекопск, Симферополь, Судак, Феодосия. По мнению авторов, эти городские округа первыми принимали удар последствий коронавируса.
Из данных рисунка 2 следует, что фактические темпы прироста отражены в Сакском районе, Симферополе и Ялте.

\section{Исполнение \\ консолидированного бюджета}

Исполнение консолидированного бюджета субъекта, бюджеты субъектов, местного бюджета по состоянию на 01.06.2018-2020 отражено на рисунке 3.

На показатели исполнения консолидированного бюджета, бюджета субъекта, местного бюджета, повлияла пандемия коронавируса, меры, которые были приняты государством, направлены в первую очередь на сохранение жизни граждан и их безопасность, сохранение рабочих мест, поддержание малого и среднего бизнеса, поддержание системы социально-экономического развития. 
Л.М. Борщ, С.В. Герасимова. Анализ эффективности региональной бюджетной политики

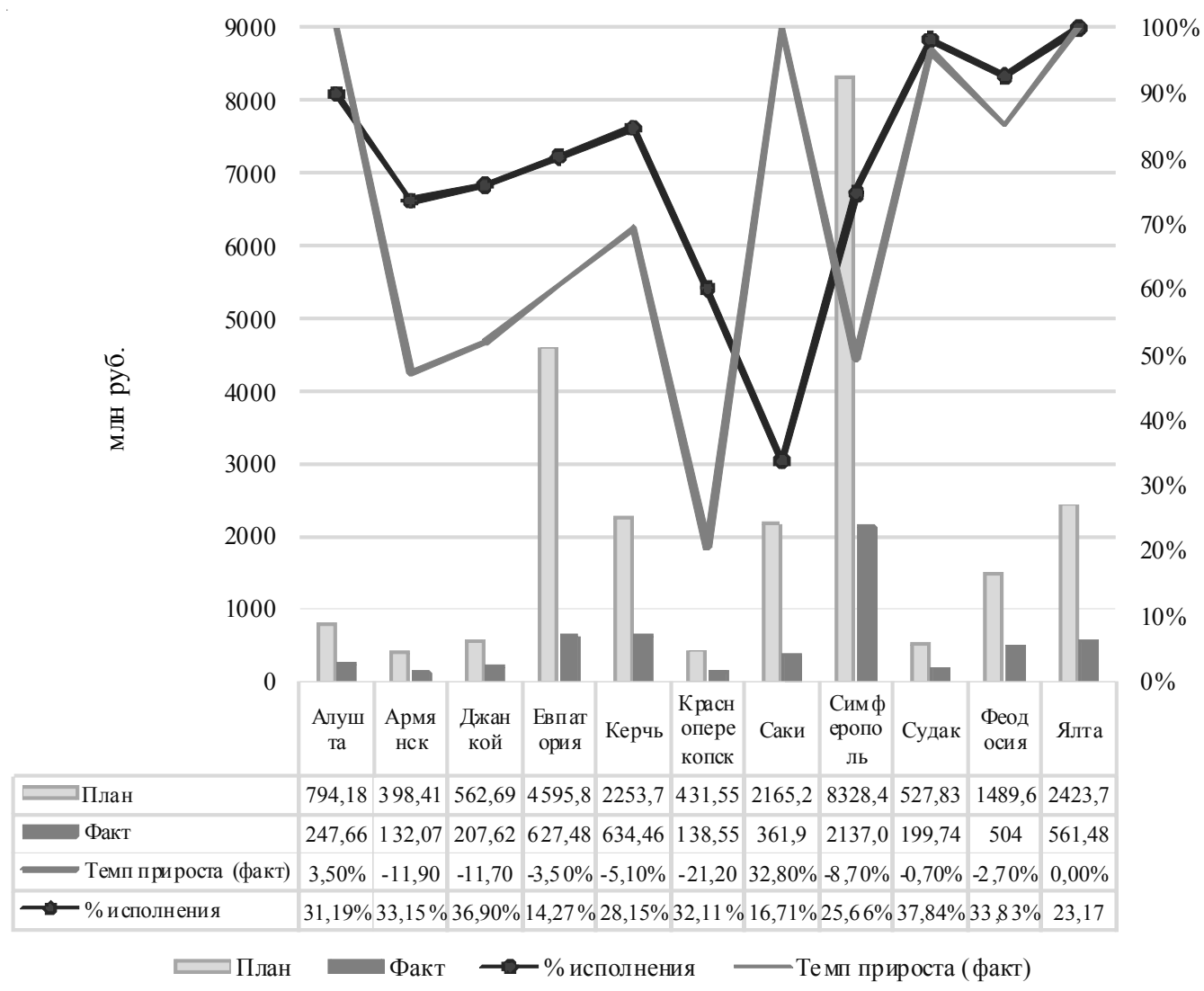

Рис. 2. Межбюджетные трансферты по городским округам по состоянию на 01.062020 Примечание. Составлено авторами по: [Официальный сайт Открытого бюджета ...].

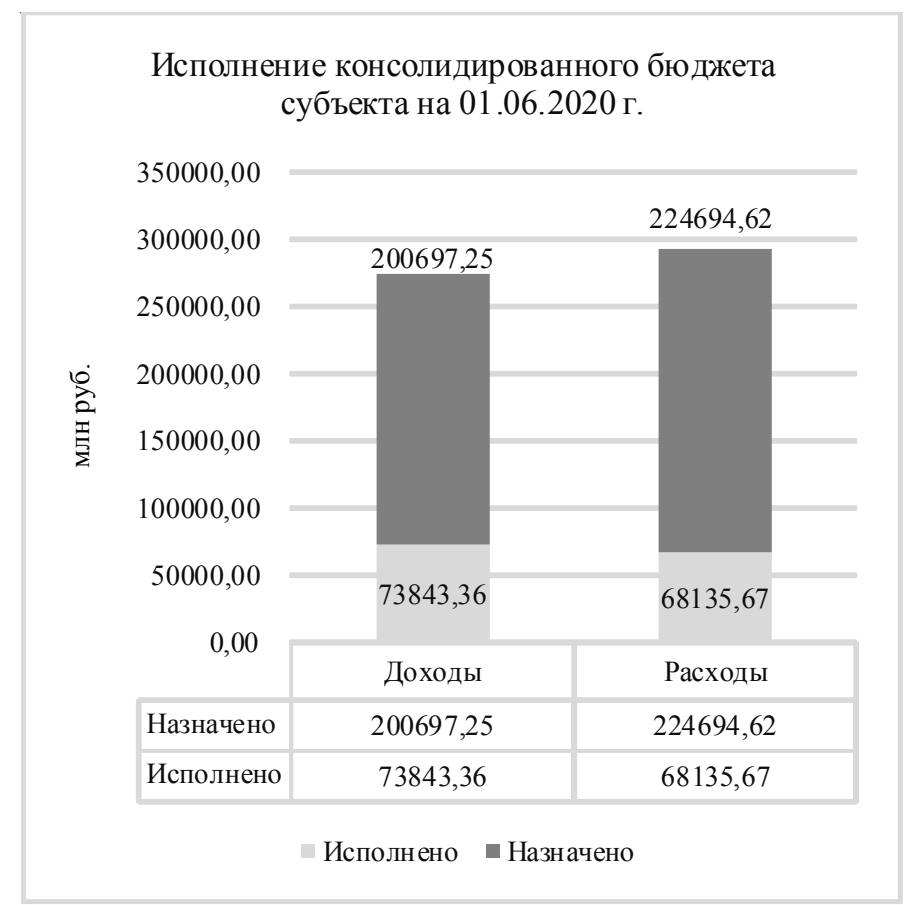

Рис. 3. Исполнение консолидированного бюджета субъекта, бюджета субъекта и местного бюджета по состоянию на 01.06.2018-2020 (см. также с. 94)

Примечание. Составлено авторами по: [Официальный сайт Открытого бюджета ...]. Численность населения - 1912025 чел.; расходы бюджета на 1 жителя - 117,52 тыс. рублей. 

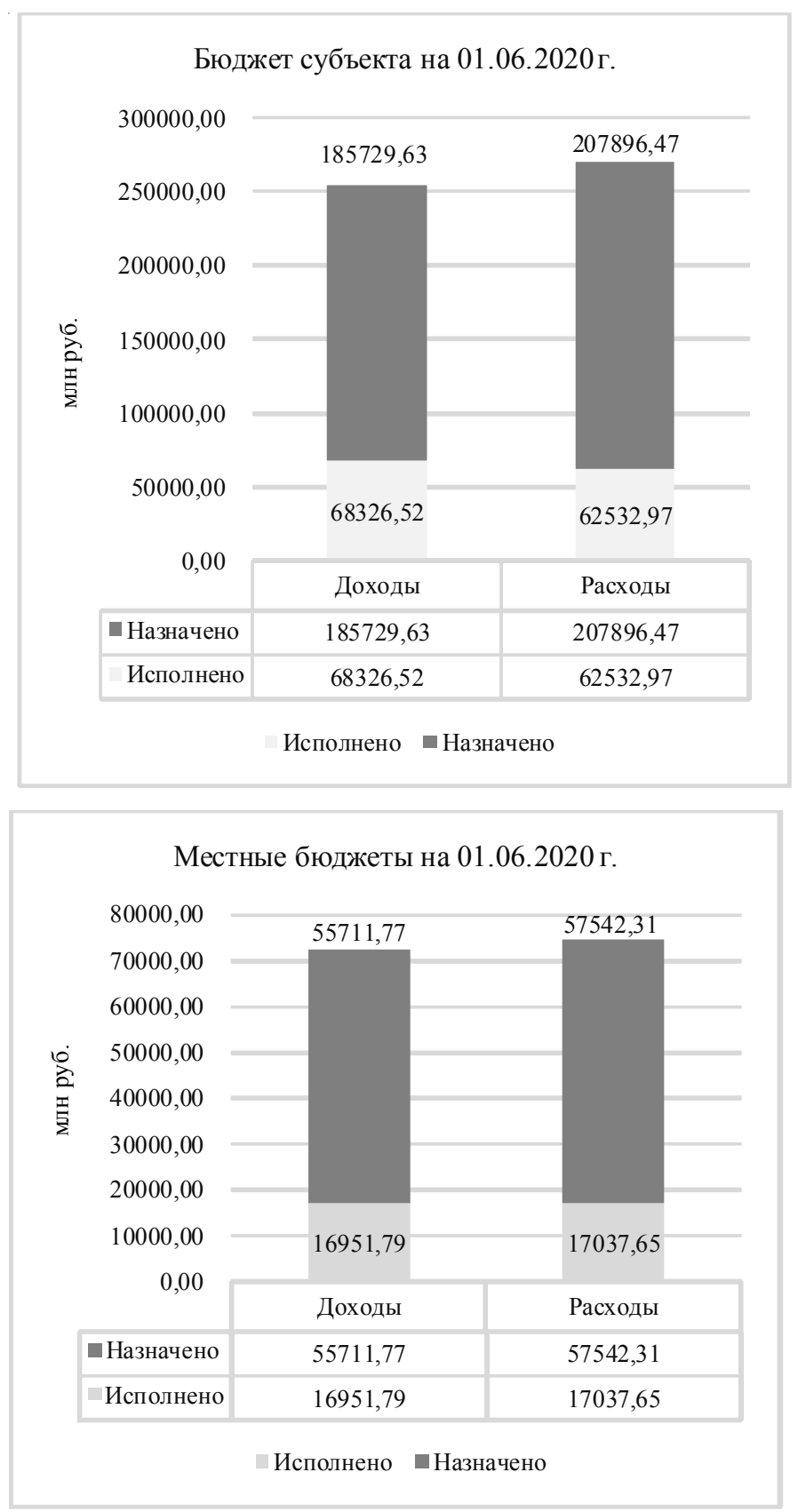

Рис. 3. Окончание

К крупнейшим налогоплательщикам Республики Крым, формирующим 14,4 \% бюджета, относятся общества с ограниченной ответственностью (расходы и дифицит консолидированного бюджета субъекта, бюджета субъекта и местного бюджета в динамике по состоянию на 2018-2020 гг. представлены на рисунке 4).

Проанализируем расходы консолидированного бюджета Республики Крым. Расходы консолидированного бюджета в 2020 г. снизились, дефицит консолидированного бюджета увеличился из-за пандемии. В бюджете субъекта в
2020 г. расходы снизились, дефицит составил 85,86 млн руб. [Официальный сайт Министерства экономического развития ...].

Данное исследование показывает, что применение методов и инструментов не всегда бывает эффективным и может влиять на увеличение долговой нагрузки региона. Проанализируем наглядно данную ситуацию на примере Республики Крым по состоянию на 01.06.2019-2020: уровень государственного долга на данную дату в 2019 г. составил 8,06 \%; в 2020 г. - 6,96\%, тенденция взяла курс на снижение $1,10 \%$. 
Консолидированный бюджет субъекта

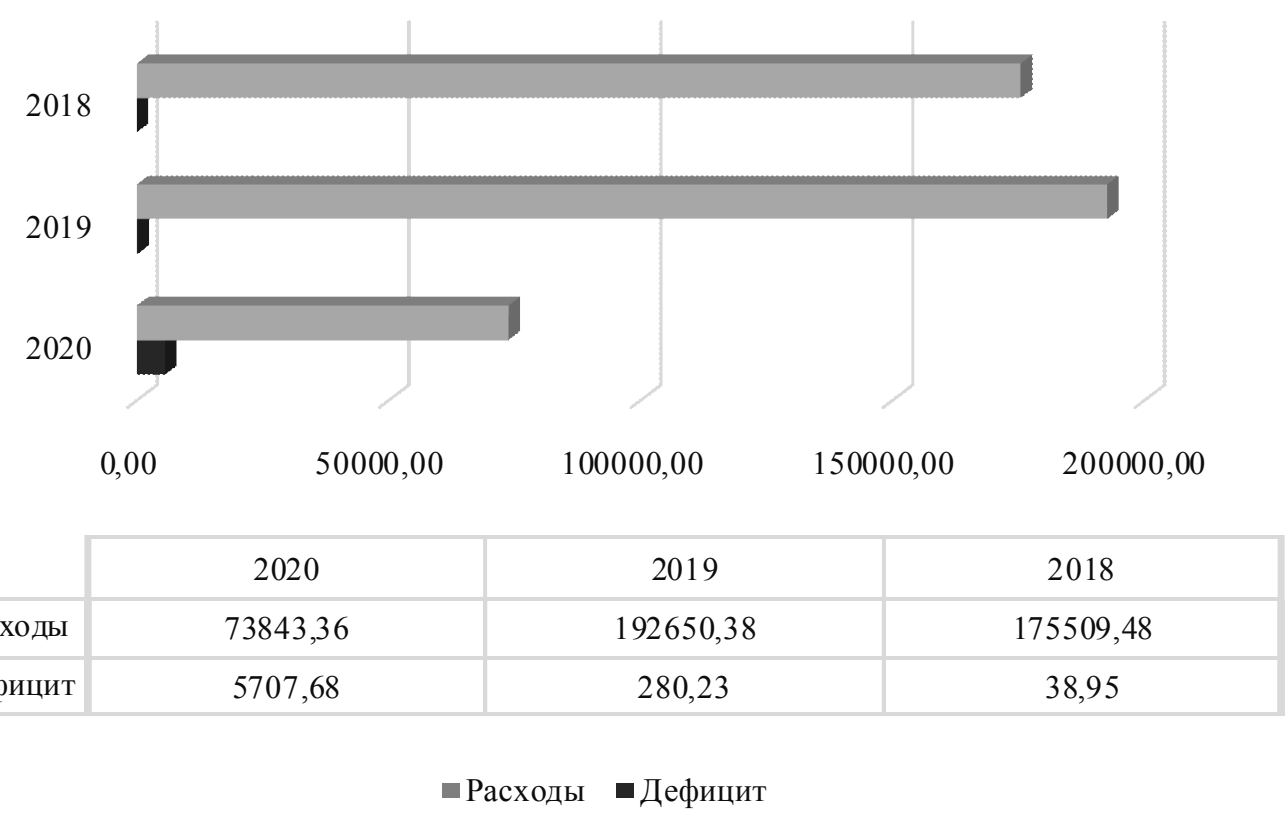

Бюджет субъекта

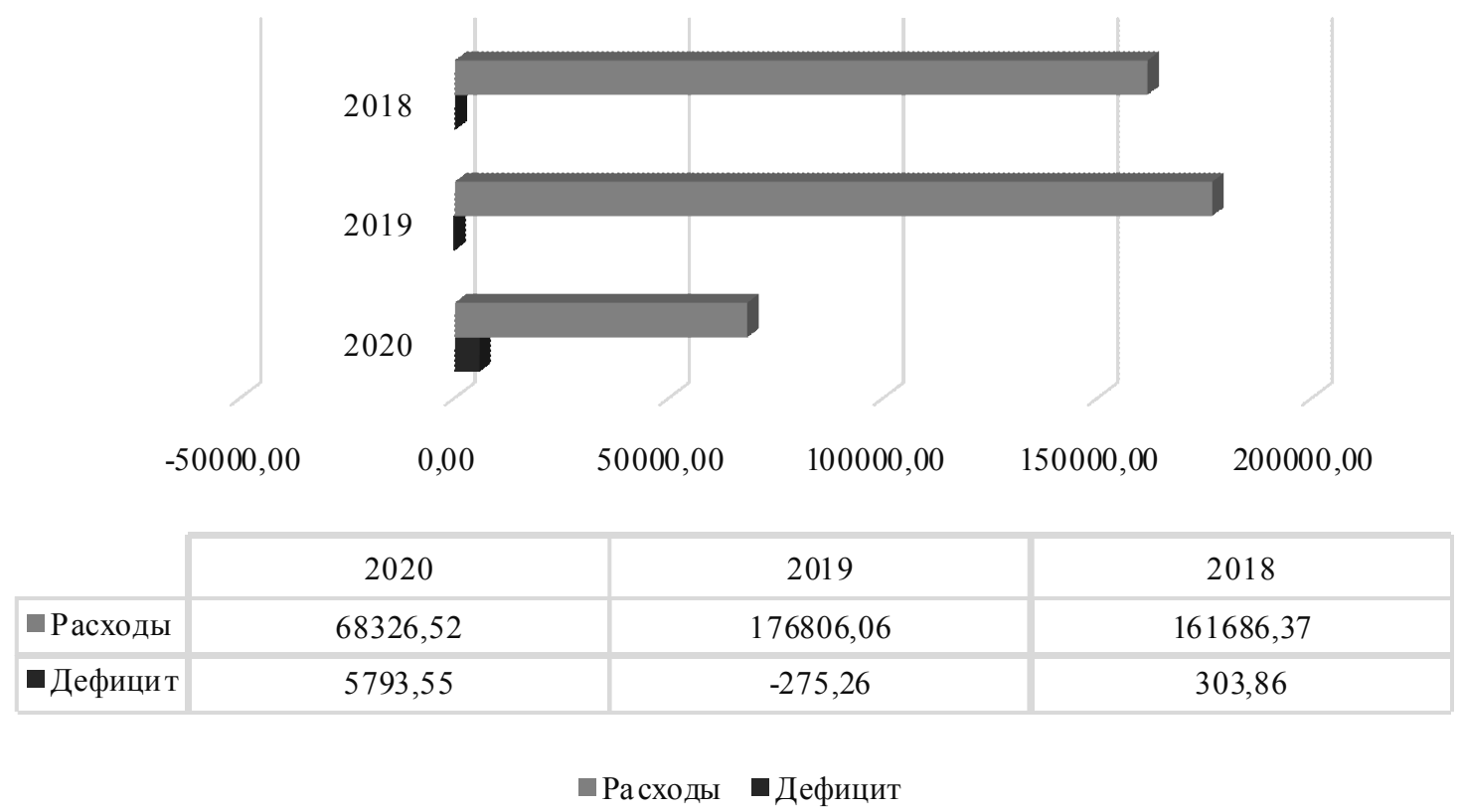

Рис. 4. Расходы и дифицит консолидированного бюджета субъекта, бюджета субъекта и местного бюджета по состоянию 2018-2020 гг., млн руб. (см. также с. 96)

Примечание. Составлено авторами по: [Официальный сайт Министерства экономического развития ...]. 
Местные бюджеты

\begin{tabular}{|c|c|c|c|c|c|c|}
\hline & 2018 & & & \\
\hline
\end{tabular}

Рис. 4. Окончание

Суммарно эти показатели выражены в млн руб. на эту же дату в 2019 г. $-3643,19$; в 2020 г. на эту дату - 3 451,44; уменьшение государственного долга по Республике Крым на 191,75 [Нормативный процесс ...].

На определенном периоде развития конкурентной экономики, способной изменять свои траектории развития и кардинально повлиять на усиление и формирование здоровой конкурентной среды, данный процесс можно осуществить при помощи создания новой модификации механизма конкуренции и ее научно-теоретической концепции, которая требует нового институционального подхода по отношению к региональному развитию. Исследования показывают, что для формирования воспроизводственных процессов необходимы совершенно новые концепции в торговых отношениях на уровне регионов, производственные, технологические, трансформационные, инвестиционные и развития цифровой инфраструктуры. Для развития сильной региональной бюджетной системы необходимо создавать предпосылки, которые закладываются в процессы управления по сбалансированию финансовой системы. Для развития и совершенствования эффективных механизмов финансовой системы необходимо гармонизировать все концепции развития, которые дополняют друг друга, но и имеют много противоречий. Также целесообразно разработать механизм общей их корреляции между собой и определить объективные критерии с определенными ус- тановленными границами, обозначить правовое обеспечение исполнения данных программ. Такие действия изменят саму культуру конкурентоспособности, произойдут процессы эффективного роста экономики, сформируются точки роста, что приведет систему к действию [Колбина, 2016, с. 12]. Ресурсы необходимо использовать бережно, ведь природная среда должна воспроизводиться, ибо это природное богатство и среда обитания человека, который влияет на процессы социально-экономического развития и бережное отношение к природной среде.

К основным показателям, влияющим на социально-экономическое развитие, относятся: валовой региональный продукт, который в 2020 г. по Республике Крым составил 499 718,18 млн руб.; индекс физического объема валового регионального продукта составил $114,20 \%$; прожиточный минимум составил 11 353,40 тыс. руб.; объем работ, выполненных по видуэкономической деятельности «строительство», выражен суммой 16 908,08 млн руб., индекс потребительских цен в \% соотношении составил 104,50; численность населения в тыс. чел составила 1998,70 [Официальный сайт Открытого бюджета ...].

Основные крупные налогоплательщики в регионе, формирующие 14,7 \% консолидированного бюджета: «К-Телеком»; Акционерное общество «ПБК Крым»; «Крымская железная дорога»; «Акционерное общество Международный аэропорт «Симферополь»; Государ- 
ственное унитарное предприятие Республики Крым «Крымэнерго»; ФГУП производственное объединение «Массандра»; Акционерное общество с ограниченной ответственностью «КД Коктебель»; ФГАОУ ВО «Крымский федеральный университет им. В.И. Вернадского»; Общество с ограниченной ответственностью «ССК Газрегион» [Официальный сайт Министерства экономического развития ...].

\section{Финансовый менеджмент как эффективный инструмент эффективного управления}

Следует также формировать региональные подходы, стимулирующие работу органов исполнительной власти, основой данных подходов является оценка эффективности деятельности органов исполнительной власти субъектов Российской Федерации.

В 2020 г. применялся финансовый менеджмент как эффективный инструмент управления в деятельности органов исполнительной власти Республики Крым (рис. 5).

Анализ степени качества финансового и бюджетного менеджмента предоставляет оценку и качественные характеристики эффек- тивной работы большинства министерств в Республике Крым. Вместе с тем не обращают особое внимание на функционирование системы оценки эффективности в Министерстве здравоохранения, Министерстве имущественных отношений и Министерстве транспорта на низкие показатели в их системе финансового менеджмента [Официальный сайт Открытого бюджета ...].

Действенность методов и инструментов влияния, применяемых Росстатом, определяется мониторингом, который отражен в Указе Президента Российской Федерации от 25 апреля 2019 г. об эффективной деятельности органов исполнительной власти субъектов Российской Федерации. Их использование зависит от основных показателей: качество жизни граждан; уровень заработной оплаты труда; ВВП; ВРП; уровень безработицы; уровень бедности.

\section{Заключение}

Таким образом, мы пришли к следующим выводам:

1. Формирование региональной бюджетной системы является сложным и комплекс-

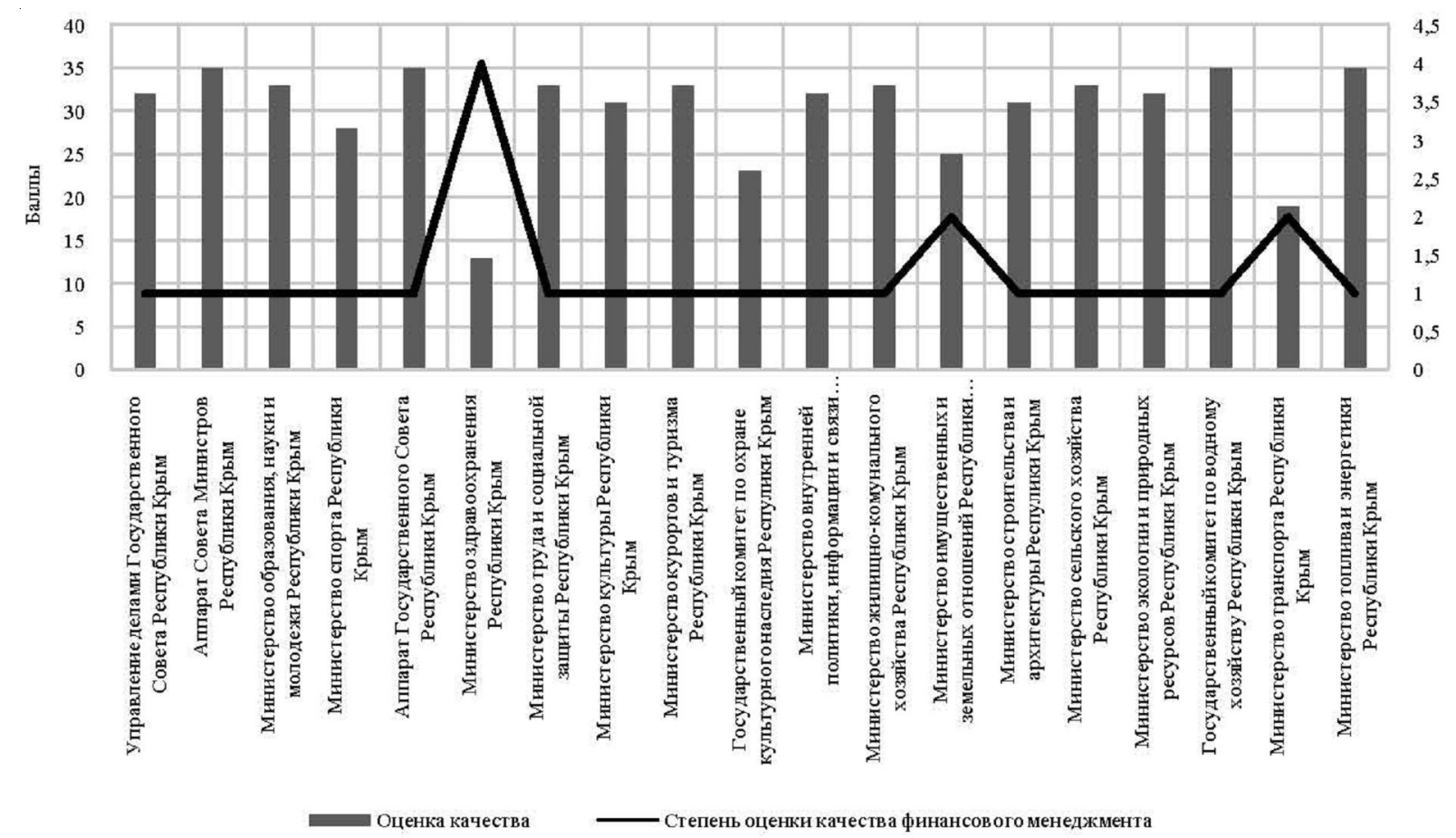

Рис. 5. Анализ степени качества финансового менеджмента

Примечание. Составлено авторами по: [Официальный сайт Министерства финансов ...]. 
ным процессом управления не только на уровне финансовой системы. Для эффективного функционирования экономики необходимо развивать всю систему промышленного производства, формировать инфраструктуру цифровую, отраслевую, управленческую, инвестиционную, инновационную, применяя методы прямого и косвенного регулирования, опираясь на поставленные цели и задачи, применяя эволюционный стратегический менеджмент, направленный на формирование конкурентных преимуществ во всех сферах как целостной региональной системы.

2. В целях эффективного управления региона необходимо производить продление периода погашения реструктурированных обязательств по бюджетным кредитам на условиях роста налоговых и неналоговых доходов консолидированного бюджета с общим сроком реструктуризации от 10 до 15 лет, эти инструменты позволят стабильно развиваться регионам.

3. На данном этапе целостное представление о региональном развитии финансовой системы, которая развивается на стыке проблемных и сложных полей и отношений, сетевой неравномерности, показывает, что применение методов и инструментов не всегда бывает эффективным и может влиять на увеличение долговой нагрузки региона.

4. Понимание цифровой экономики состоит из формирования цифровой инфраструктуры в финансовой системе, что сократит множество трансакций и время для эффективного управления финансовыми ресурсами. Цифровая инфраструктура даст толчок развитию финансовой системы и цифровой экономики, что приведет к росту наукоемких производств, росту воспроизводственных процессов и станет локомотивом экономического развития в целом.

5. Сформируется сетевое ядро цифровой инфраструктуры, которое обеспечит доступ организаций к получению новых баз ресурсов, знаний, типам рент, возможностям развивать производственные мощности, тем самым повышать и наращивать конкурентные преимущества, что повлияет на формирование доходной части бюджета и поспособствует притоку инвестиций в высокотехнологичные производства.
6. Для повышения эффективности и равномерности регионального развития и усиления бюджетной политики необходимо постоянно совершенствовать бюджетную систему государственного регулирования. Современное состояние бюджетной системы по планированию и прогнозированию бюджета региона характеризуется множеством дублирующих функций в разных органах государственной власти, что в итоге снижает эффективность.

\section{СПИСОК ЛИТЕРАТУРЫ}

Борщ, Л. М. Применение инструментов денежнокредитной политики / Л. М. Борщ, А. А. Заиченко // Научный вестник: финансы, банки, инвестиции. - 2016. - № 4 (37). - С. 71-76.

Борщ, Л. М. Система межбюджетных отношений. Источники формирования консолидированного бюджета / Л. М. Борщ // Научный вестник: финансы, банки, инвестиции. - 2019. № 3 (48). - C. 5-12.

Бугаева, Т. Н. Трансформационные процессы в финансовой системе государства / Т. Н. Бугаева // Научный вестник: финансы, банки, инвестиции. - 2019. - № 3 (48). - С. 23-31.

Буркальцева, Д. Д. Приоритеты формирования эффективной региональной хозяйственной системы: инновации и инвестиции / Д. Д. Буркальцева, Л. М. Борщ, С. В. Герасимова // Вестник Екатерининского института. - 2017. № 1 (37). - C. 79-82.

Воробьев, Ю. Н. Финансовая система: комплексный подход в контексте государственной финансовой политики / Ю. Н. Воробьев, Л. М. Борщ // Финансы: теория и практика. - 2018. - Т. 22, №5 (107). - C. 56-75.

Воробьева, Е. И. Обеспечение устойчивости финансовой системы Российской Федерации в условиях глобализации / Е. И. Воробьева // Научный вестник финансы, банки, инвестиции. - 2020. - № 1. - С. 5-12.

Галюкшова, Т. В. Аргументы в налоговых спорах по НДС / Т. В. Галюкшова // Вестник Омского университета. - 2014. - № 1. - С. 157-162.

Государственный фискальный контроль в Российской федерации: проблемы и пути повышения его эффективности / М. Н. Дудин [и др.] // Финансы: теория и практика. - 2017. - Т. 21 , № $4(100)$. - C. 160-169.

Ильин, А. В. Конкуренция судопроизводств и незащищенность налогоплательщика в налоговой системе России / А. В. Ильин // Проблемы 
современной экономики. - 2014. - № 3 (51). C. $118-121$.

Колбина, Л. С. С аппетитом к рынку / Л. С. Колбина // Эксперт Урал. - 2016. - № 35. - С. 11-15.

Комментарий к Федеральному закону от 0307.2017 // Сводная коллекция ЭБС. - Электрон. текстовые дан. - Режим доступа: https://book.ru (дата обращения: 26.11.2020). - Загл. с экрана.

Митрофанова, И. В. Региональное стратегирование: некоторые итоги 2014-2017 годов / И. В. Митрофанова, Н. С. Мельникова, В. В. Батманова // Региональная экономика. Юг России. 2018. - № 1 (19). - С. 75-84.

Мосейкин, В. В. Налоговый контроль в системе налогового администрирования Российской Федерации / В. В. Мосейкин // Вестник Омского университета. - 2014. - № 1. - С. 163-167.

Нормативный процесс в Республике Крым от 26 октября 2019 г. // Коллекция Научной электронной библиотеки. - Электрон. текстовые дан. Режим доступа: https:/elibrary.ru (дата обращения: 26.11.2020). - Загл. с экрана.

Официальный сайт Министерства финансов Российской Федерации. - Электрон. текстовые дан. - Режим доступа: https:// minfin.gov.ru/ru (дата обращения: 26.11.2020). - Загл. с экрана.

Официальный сайт Министерства экономического развития Российской Федерации. - Электрон. текстовые дан. - Режим доступа: http:// economy.gov.ru (дата обращения: 26.11.2020). Загл. с экрана.

Официальный сайт Открытого бюджета Республики Крым. - Электрон. текстовые дан. - Режим доступа: https://budget.rk.ifinmon.ru/ (дата обращения: 26.11.2020). - Загл. с экрана.

Родионова, А. И. Анализ и оценка эффективности налогового контроля (на примере города Курска) / А. И. Родионова, Н. С. Трусова // Экономика и менеджмент инновационных технологий. -2015. - № 1 (40). - С. 138-141.

Савина, О. Н. Формирование доходной базы местных бюджетов в условиях стратегических преобразований / О. Н. Савина, Н. П. Паздникова, Д. А. Шелестова // Региональная экономика. Юг России. - 2018. - № 2. - С. 129-138.

Савинкова, Т. А. Оценка эффективности организации налогового контроля / Т. А. Савинкова, А. С. Ниятбаева, В. Д. Сирина // Экономика и менеджмент инновационных технологий. 2017. - № 1 (64). - С. 39-42.

Тажитдинов, И. А. Применение стейкхолдерского подхода в стратегическом управлении развития территорий / И. А. Тажитдинов // Экономика региона. - 2013. - № 2 (34). - С. 17-27.

Тараканов, В. В. Механизм финансового стимулирования инвестиционной деятельности / В. В. Та- раканов, А. А. Калашников // Вестник Волгоградского государственного университета. Серия 3, Экономика. Экология. - 2016. - № 1 (34). C. 98-105.

Чернова, О. А. Методический инструментарий разработки стратегии регионального развития: новые подходы / О. А. Чернова, Н. П. Иванов // Региональная экономика. Юг России. - 2018. № 1(19).-С. 65-74.

\section{REFERENCES}

Borsch L.M., Zaichenko A.A. Primenenie instrumentov denezhno-kreditnoj politiki [Application of Monetary Policy Instruments]. Nauchnyj vestnik: finansy, banki, investicii [Scientific Bulletin: Finance, Banks, Investments], 2016, no. 4 (37), pp. 71-76.

Borsch L.M. Sistema mezhbyudzhetnyh otnoshenij. Istochniki formirovaniya konsolidirovannogo byudzheta [The System of Inter Budgetary Relations. Sources of Formation of the Consolidated Budget]. Nauchnyj vestnik: finansy, banki, investicii [Scientific Bulletin: Finance, Banks, Investments], 2019, no. 3 (48), pp. 5-12.

Bugaeva T.N. Transformacionnye processy v finansovoj sisteme gosudarstva [Transformational Processes in the Financial System of the State]. Nauchnyj vestnik: finansy, banki, investicii [Scientific Bulletin: Finance, Banks, Investments], 2019, no. 3 (48), pp. 23-31.

Burkalceva D.D., Borsch L.M., Gerasimova S.V. Prioritety formirovaniya effektivnoj regionalnoj hozyajstvennoj sistemy: innovacii i investicii [Priorities for the Formation of an Effective Regional Economic System: Innovation and Investment]. Vestnik Ekaterininskogo instituta [Bulletin of the Catherin Institute], 2017, no. 1 (37), pp. 79-82.

Vorobev Yu.N., Borsh L.M. Finansovaya sistema: kompleksnyj podhod $v$ kontekste gosudarstvennoj finansovoj politiki [Financial System: An Integrated Approach in the Context of Public Financial Policy]. Finansy: teoriya $i$ praktika [Finance: Theory and Practice], 2018, vol. 22, no. 5(107), pp. 56-75.

Vorobeva E.I. Obespechenie ustojchivosti finansovoj sistemy Rossijskoj Federacii v usloviyah globalizacii [Ensuring of the Stability of the Financial System of the Russian Federation in the Context of Globalization]. Nauchnyj vestnik finansy, banki, investicii [Scientific Bulletin: Finance, Banks, Investments], 2020, no. 1, pp. 5-12. 
Galyukshova T.V. Argumenty v nalogovyh sporah po NDS [Argument in VAT Tax Disputes]. Vestnik Omskogo universiteta [Omsk University Bulletin], 2014, no. 1.pp. 157-162.

Dudin M.N., Burkalceva D.D., Vorobev Yu.N., Borsh L.M., Dombrovskaya E.K. Gosudarstvennyj fiskalnyj kontrol v Rossijskoj federacii: problemy i puti povysheniya ego effektivnosti [State Fiscal Control in the Russian Federation: Problems and Ways to Improve Its Efficiency]. Finansy: teoriya $i$ praktika [Finance: Theory and Practice], 2017, vol. 21, no. 4 (100), pp. 160-169.

Ilin A.V. Konkurenciya sudoproizvodstv i nezashishennost nalogoplatelshika $v$ nalogovoj sisteme Rossii [Competition of Legal Proceedings and the Lack of Tax Payer Protection in Russian Taxation System (Russia, Novosibirsk)]. Problemy sovremennoj ekonomiki [Problems of Modern Economy], 2014, no. 3 (51), pp. 118-121.

Kolbina L.S. S appetitom k rynku [With an Appetite for the Market]. Ekspert Ural [Expert Ural], 2016, no. 35, pp. 11-15.

Kommentarii k Federalnomu zakonu ot $0307.2017 \mathrm{~g}$. [Commentary to the Federal Law of 03.07.2017]. Svodnaya kollekciya EBS [Summary Collection of the Electronic Library System]. URL: https:// book.ru (accessed 26 November 2020).

Mitrofanova I.V., Melnikova N.S., Batmanova V.V. Regionalnoe strategirovanie: nekotorye itogi 2014-2017 godov [Regional Strategizing: Some Results of 2014-2017]. Regionalnaya ekonomika. Yug Rossii [Regional Economy. South of Russia], 2018, no. 1 (19), pp. 75-84.

Mosejkin V.V. Nalogovyj kontrol v sisteme nalogovogo administrirovaniya Rossijskoj Federacii [Tax Control in the System of Tax Administration of the Russian Federation]. Vestnik Omskogo universiteta [Bulletin of Omsk University], 2014, no. 1, pp. 163-167.

Normativnyj process $v$ Respublike Krym ot 26 oktyabrya 2019 g. [Regulatory Process in the Crimea Dated 26 October 2019]. URL: https:/ /elibrary.ru/ (accessed 26 November 2020).

Ofitsialnyy sayt Ministerstva finansov Rossijskoj Federacii [Official Website of the Ministry of Finance of the Russian Federation]. URL: https:// minfin.gov.ru/ ru/ (accessed 26 November 2020).

Ofitsialnyy sayt Ministerstva ekonomicheskogo razvitiya Rossijskoj Federacii [Official Website of the Ministry of Economic Development of the Russian Federation]. URL http://economy. gov.ru (accessed 26 November 2020).

Ofitsialnyy sayt Otkrytogo byudzheta Respubliki Krym [Official Website of the Open Budget of the Republic of Crimea]. URL: https://budget. rk.ifinmon.ru/ (accessed 26 November 2020).

Rodionova A.I., Trusova N.S. Analiz i ocenka effektivnosti nalogovogo kontrolya (na primere goroda Kurska) [Analysis and Assessment of the Effectiveness of Tax Control (For Example, the City of Kursk)]. Ekonomika i menedzhment innovacionnyh tehnologij [Economics and Management of Innovative Technologies], 2015, no. 1 (40), pp. 138-141.

Savina O.N., Pazdnikova N.P., Shelestova D.A. Formirovanie dohodnoj bazy mestnyh byudzhetov v usloviyah strategicheskih preobrazovanij [Formation of the Revenue Base of Local Budgets in the Context of Strategic Transformations]. Regionalnaya ekonomika. Yug Rossii [Regional Economy. South of Russia], 2018, no. 2, pp. 129-138.

Savinkova T.A., Niyatbaeva A.S., Sirina V.D. Ocenka effektivnosti organizacii nalogovogo kontrolya [Assessments of the Effectiveness of the Organization of Tax Control]. Ekonomika $i$ menedzhment innovacionnyh tehnologij [Economics and Management of Innovative Technologies], 2017, no. 1 (64), pp. 39-42.

Tazhitdinov I.A. Primenenie stejkholderskogo podhoda $v$ strategicheskom upravlenii razvitiya territorij [Application of the Stakeholder Approach in Strategic Management of Territorial Development]. Ekonomika regiona [Economy of the Region], 2013, no. 2 (34), pp. 17-27.

Tarakanov V.V., Kalashnikov A.A. Mehanizm finansovogo stimulirovaniya investicionnoj deyatelnosti [The Mechanism of Financial Stimulation of Investment Activity]. Vestnik Volgogradskogo gosudarstvennogo universiteta. Seriya 3, Ekonomika. Ekologiya [Science Journal of Volgograd State University. Global Economic System], 2016, no. 1 (34), pp. 98-105.

Chernova O.A., Ivanov N.P. Metodicheskij instrumentarij razrabotki strategii regionalnogo razvitiya: novye podhody [Methodological Tools for Developing a Regional Development Strategy: New Approaches]. Regionalnaya ekonomika. Yug Rossii [Regional Economy. South of Russia], 2018, no. 1 (19), pp. 65-74. 


\section{Information About the Authors}

Lyudmila M. Borsch, Doctor of Sciences (Economics), Professor, Department of Finance of Enterprises and Credit, Institute of Economics and Management, V.I. Vernadsky Crimean Federal University, Prosp. Akademika Vernadskogo, 4, 295007 Simferopol, Russian Federation, 1-borsh49@mail.ru, https://orcid.org/0000-0001-7729-3022

Svetlana V. Gerasimova, Doctor of Sciences (Economics), Professor, Department of Business Informatics and Mathematical Modeling, Institute of Economics and Management, V.I. Vernadsky Crimean Federal University, Prosp. Akademika Vernadskogo, 4, 295007 Simferopol, Russian Federation, svetlana-gerasimova-68@mail.ru, https://orcid.org/0000-0002-7077-6352

\section{Информация об авторах}

Людмила Михайловна Борщ, доктор экономических наук, профессор кафедры финансов предприятий и страхования, Институт экономики и управления, Крымский федеральный университет им. В.И. Вернадского, просп. Академика Вернадского, 4, 295007 г. Симферополь, Российская Федерация, 1-borsh49@mail.ru, https://orcid.org/0000-0001-7729-3022

Светлана Васильевна Герасимова, доктор экономических наук, профессор кафедры бизнесинформатики и математического моделирования, Институт экономики и управления, Крымский федеральный университет им. В.И. Вернадского, просп. Академика Вернадского, 4, 295007 г. Симферополь, Российская Федерация, svetlana-gerasimova-68@mail.ru, https://orcid.org/0000-0002-7077-6352 